\title{
Estimation of Protein Content in Rice Crop and Nitrogen Content in Rice Leaves Through Regression Analysis with NDVI Derived from Camera Mounted Radio-Control Helicopter
}

\author{
Kohei Arai ${ }^{1}$ \\ Graduate School of Science and Engineering \\ Saga University \\ Saga City, Japan \\ Masanori Sakashita \\ Department of Information Science \\ Saga University \\ Saga City, Japan
}

\author{
Osamu Shigetomi \\ Saga Prefectural Agricultural Research Institute \\ Saga Prefecture \\ Saga City, Japan \\ Yuko Miura \\ Saga Prefectural Agricultural Research Institute \\ Saga Prefecture \\ Saga City, Japan
}

\begin{abstract}
Estimation of protein content in rice crop and nitrogen content in rice leaves through regression analysis with Normalized Difference Vegetation Index: NDVI derived from camera mounted radio-control helicopter is proposed. Through experiments at rice paddy fields which is situated at Saga Prefectural Research Institute of Agriculture: SPRIA in Saga city, Japan, it is found that protein content in rice crops is highly correlated with NDVI which is acquired with visible and Near Infrared: NIR camera mounted on radio-control helicopter. It also is found that nitrogen content in rice leaves is correlated to NDVI as well. Protein content in rice crop is negatively proportional to rice taste. Therefore rice crop quality can be evaluated through NDVI observation of rice paddy field.
\end{abstract}

Keywords-nitrogen content; NDVI; protein content; rice paddy field; remote sensing; regression analysis

\section{INTRODUCTION}

There are strong demands for saving human resources which are required for produce agricultural plants. In particular in Japan, now a day, the number of working peoples for agricultural fields is decreasing quite recently. Furthermore, the ages of the working peoples are getting old. Moreover, the agricultural fields are also getting wide through merging a plenty of relatively small scale of agricultural fields in order for maintain the fields in an efficient manner. Therefore, the working peoples have to maintain their fields in an efficient manner keeping the quality in mind.

Vitality monitoring of vegetation is attempted with photographic cameras [1]. Grow rate monitoring is also attempted with spectral reflectance measurements [2]. BiDirectional Reflectance Distribution Function: BRDF is related to the grow rate for tealeaves [3]. Using such relation, sensor network system with visible and near infrared cameras is proposed [4]. It is applicable to estimate nitrogen content and fiber content in the tealeaves in concern [5]. Therefore, damage grade can be estimated with the proposed system for rice paddy fields [6]. This method is validated with Monte Carlo simulation [7]. Also Fractal model is applied to representation of shapes of tealeaves [8]. Thus the tealeaves can be asse3ssed with parameters of the fractal model. Vitality of tea trees are assessed with visible and near infrared camera data [9]. Rice paddy field monitoring with radio-control helicopter mounting visible and NIR camera is proposed [10] while the method for rice quality evaluation through nitrogen content in rice leaves is also proposed [11]. The method proposed here is to evaluate rice quality through protein content in rice crop with observation of NDVI which is acquired with visible and NIR camera mounted on radio-control helicopter.

The proposed method and system is described in the next section followed by experiments. The experimental results are validated in the following section followed by conclusion with some discussions.

\section{PROPOSED Method AND System}

\section{A. Radio Controlled Helicopter Based Near Infrared}

Cameras Utilizing Agricultural Field Monitoring System

The helicopter used for the proposed system is "GrassHOPPER" ${ }^{1}$ manufactured by Information \& Science Techno-Systems Co. Ltd. The major specification of the radio controlled helicopter used is shown in Table 1. Also, outlook of the helicopter is shown in Figure 1. Canon Powershot $\mathrm{S}_{100^{2}}$ (focal length $=24 \mathrm{~mm}$ ) is mounted on the GrassHOPPER. It

${ }_{2}^{1} \mathrm{http}: / / \mathrm{www}$. ists.co.jp/?page_id=892

http://cweb.canon.jp/camera/dcam/lineup/powershot/s110/inde x.html 
allows acquire images with the following Instantaneous Field of View: IFOV at the certain altitudes, $1.1 \mathrm{~cm}$ (Altitude $=30 \mathrm{~m}$ )

$3.3 \mathrm{~cm}$ (Altitude $=100 \mathrm{~m}$ ) and $5.5 \mathrm{~cm}$ (Altitude $=150 \mathrm{~m})$.

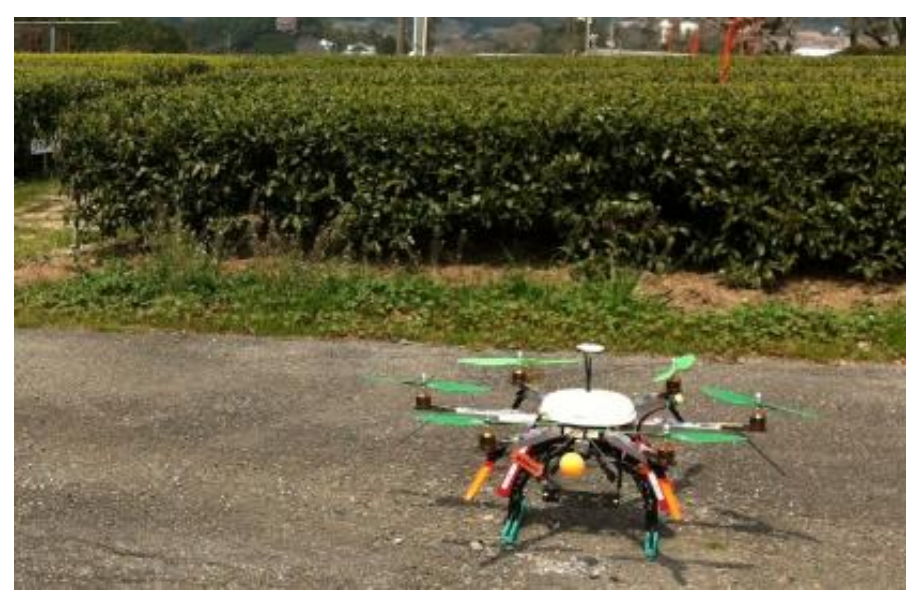

Fig. 1. Outlook of the GrassHOPPER

TABLE I. MAJOR SPECIFICATION OF GRASSHOPPER

\begin{tabular}{|l|l|}
\hline Weight & $2 \mathrm{~kg}$ (Helicopter only) \\
\hline Size & $80 \mathrm{~cm} \times 80 \mathrm{~cm} \times 30 \mathrm{~m}$ \\
\hline Payload & $600 \mathrm{~g}$ \\
\hline
\end{tabular}

Spectral response functions of filters attached to the camera used are shown in Figure 2.

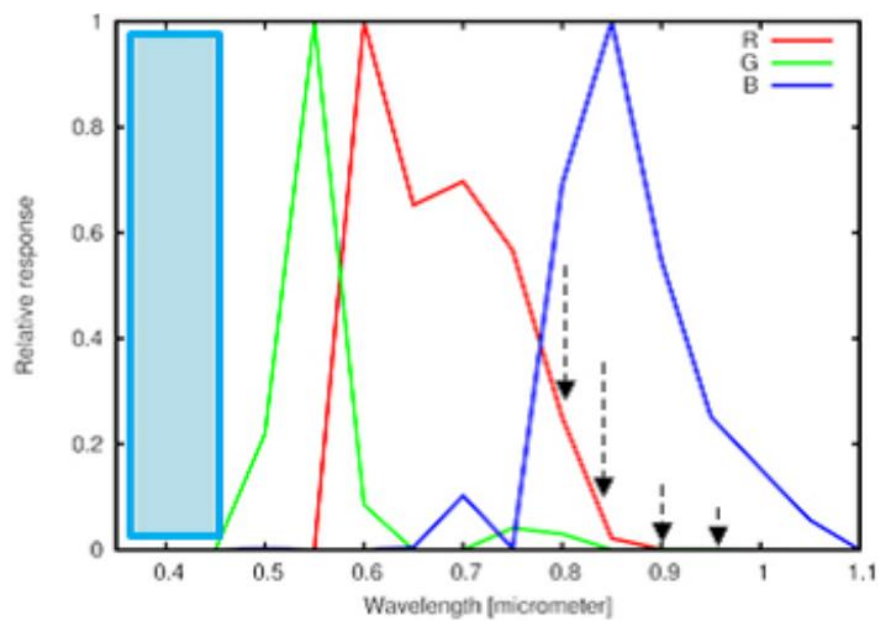

Fig. 2. Spectral Response of the Filter attached to Camera

In order to measure NIR reflectance, standard plaque whose reflectance is known is required. Spectralon ${ }^{3}$ provided by Labsphere Co. Ltd. is well known as well qualified standard plaque. It is not so cheap that photo print papers are used for

3

https://www.google.co.jp/search?q=spectral+labsphere\&hl=ja the proposed system. Therefore, comparative study is needed between Spectralon and the photo print papers.

The proposed system consist Helicopter, NIR camera, photo print paper. Namely, photo print paper is put on the agricultural plantations, tea trees in this case. Then farm areas are observed with helicopter mounted Visible and NIR camera. Nitrogen content in agricultural plants, rice crops in this case, is estimated with NIR reflectance.

\section{B. Regressive Analysis}

Linear regressive equation is expressed in equation (1).

$N=a R+b$

where $N, R$ denotes measured Nitrogen content in leaves as well as protein content in rice crops, and measured NDVI derived from visible and Near Infrared: NIR reflectance, respectively while $a$ and $b$ denotes regressive coefficients. There is well known relation between nitrogen content as well as protein content in rice crops and NDVI. Therefore, regressive analysis based on equation (1) is appropriate.

\section{Proposed Method for Rice Crop Quality Evaluation}

Rice crop quality can be represented with nitrogen content which are closely related to NDVI. Furthermore, it is well known that nitrogen content rich rice crops taste good while protein content rich rice crops taste bad. Therefore, rice crops quality can be evaluated with measured NDVI measured with camera data which is mounted on radio-control helicopter.

The proposed method and rice paddy field monitoring system with visible and NIR camera which is mounted on radio-control helicopter is based on the aforementioned scientific background.

\section{Rice Crop Field at Saga Prefectural Agricultural Research Institute: SPARI}

Specie of the rice crop is Hiyokumochi ${ }^{4}$ which is one of the late growing types of rice species. Hiyokumochi is one of low amylase (and amylopectin rich) of rice species (Rice No.216).

Figure 3 and 4 shows layout of the test site of rice crop field

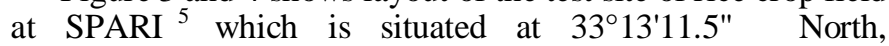
$130^{\circ} 18^{\prime} 39.6^{\prime \prime E a s t, ~ a n d ~ t h e ~ e l e v a t i o n ~ o f ~} 52 \mathrm{feet}$.

The paddy field C4-2 is for the investigation of water supply condition on rice crop quality. There are 14 of the paddy field subsections of which water supply conditions are different each other.

There are two types of water supply scheduling, short term and standard term. Water supply is stopped in the early stage of rice crop growing period for the short term water supply subsection fields while water supply is continued comparatively longer time period comparing to the short term water supply subsection fields.

4

http://ja.wikipedia.org/wiki/\%E3\%82\%82\%E3\%81\%A1\%E7 $\%$ B $1 \%$ B3

${ }^{5}$ http://www.pref.saga.lg.jp/web/shigoto/_1075/_32933/ns-

nousisetu/nouse/n_seika_h23.html 
C4-2

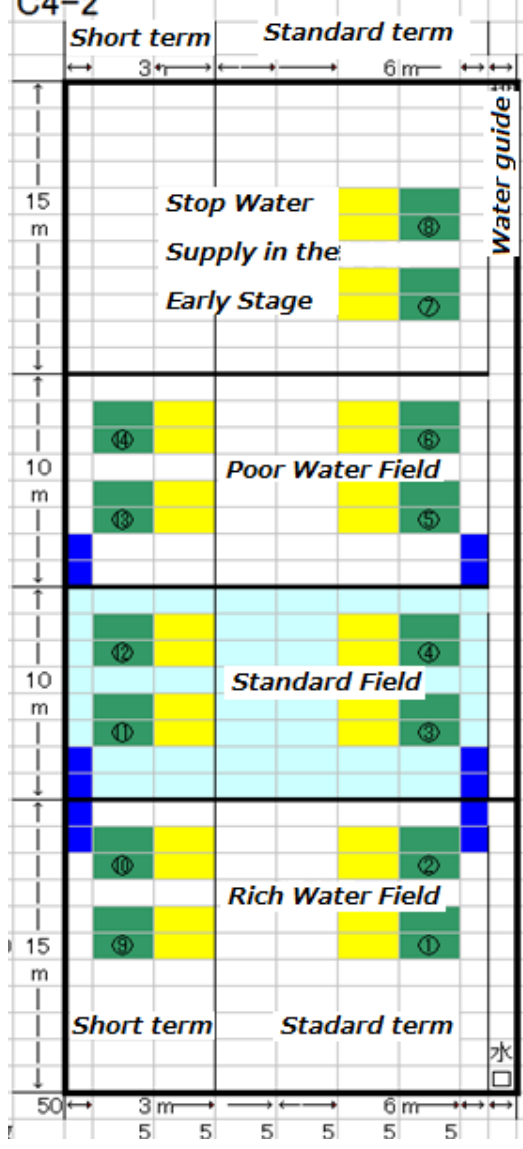

Fig. 3. Paddy field layout for investigation of water supply condition dependency on rice crop quality

Meanwhile, there are three types of water supply conditions, rich, standard, and poor water supply subsection fields.

On the other hand, test sites C4-3 and C4-4 are for investigation of nitrogen of chemical fertilizer dependency on rice crop quality. There are two types of paddy subsections, densely and sparsely planted paddy fields. Hiyokumochi rice leaves are planted 15 to 20 fluxes per $\mathrm{m}^{2}$ on June 22 2012. Rice crop fields are divided into 10 different small fields depending on the amount of nutrition including nitrogen ranges from zero to $19 \mathrm{~kg} / 10 \mathrm{a} /$ nitrogen.

Nitrogen of chemical fertilizer is used to put into paddy fields for five times during from June to August. Although rice crops in the 10 different small fields are same species, the way for giving chemical fertilizer are different. Namely, the small field No.1 is defined as there is no chemical fertilizer at all for the field while 9,11 , and $13 \mathrm{~kg} / 10 \mathrm{a} /$ nitrogen of after chemical fertilizer are given for No.2 to 4 , respectively, no initial chemical fertilizer though. Meanwhile, 9, 11, $13 \mathrm{~kg} / 10$ a/nitrogen are given as after chemical fertilizer for the small field No.5, 6, and 7, respectively in addition to the $3 \mathrm{~kg} / 10$ a/nitrogen of initial chemical fertilizer. On the other hand, 12, 14 , and $16 \mathrm{~kg} / 10 \mathrm{a} /$ nitrogen are given for the small fields No.5, 6,7 , respectively as after chemical fertilizer in addition to the initial chemical fertilizer of $3 \mathrm{~kg} / 10 \mathrm{a} /$ nitrogen for the small field No. 15, 17, 19, respectively. Therefore, rice crop grow rate differs each other paddy fields depending on the amount of nitrogen of chemical fertilizer.

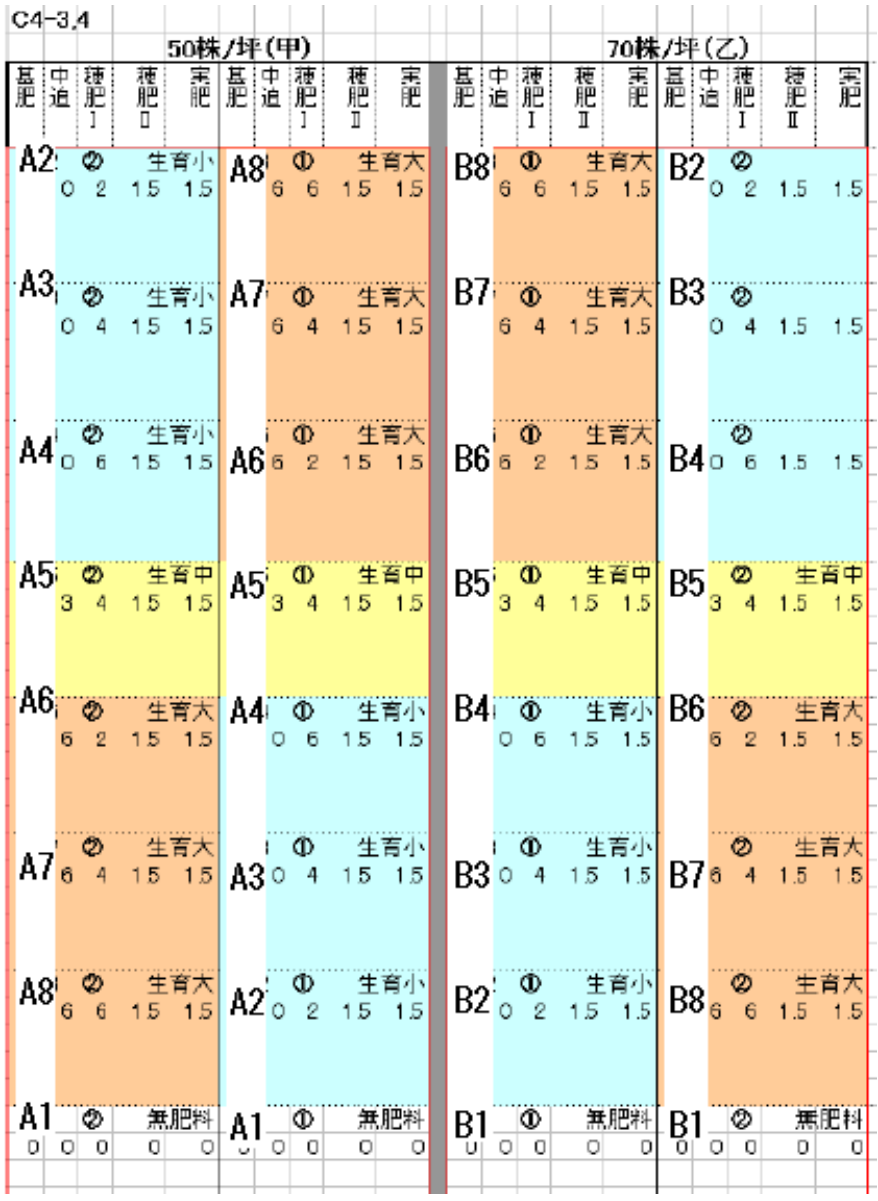

Fig. 4. Paddy filed layout for investigation of nitrogen of chemical fertilizer dependency on rice crop quality

\section{EXPERIMENTS}

\section{A. Acquired Near Infrared Camera Imagery Data}

Radio wave controlled helicopter mounted near infrared camera imagery data is acquired at C4-2, C4-3, C4-4 in SPARI on 18 and 22 August 2013 with the different viewing angle from the different altitudes. Figure 4 shows an example of the acquired near infrared image. There is spectralon of standard plaque as a reference of the measured reflectance in between C4-3 and C4-4. Just before the data acquisition, some of rice crops and leaves are removed from the subsection of paddy fields for inspection of nitrogen content. Using the removed rice leaves, nitrogen content in the rice leaves is measured based on the Keldar method and Dumas method ${ }^{6}$ (a kind of chemical method) with Sumigraph NC-220F ${ }^{7}$ of instrument. The measured total nitrogen content in rice leaves and protein content in rice crops are compared to the NDVI.

\footnotetext{
${ }_{7}^{6} \mathrm{http}: / /$ note.chiebukuro.yahoo.co.jp/detail/n92075
}

http://www.scas.co.jp/service/apparatus/elemental_analyzer/su migraph_nc-220F.html 
Example of the acquired image is shown in Figure 5. Rice field name is annotated in the image. On the other hand, the acquired camera images on 18 August and 22 August are shown in Figure 6 (a) and (b), respectively. Meanwhile, these images have influences due to shadow and shade of rice leaves and water situated under the rice leaves as well as narrow roads between rice paddy fields. In order to eliminate the influences, thresholding process is applied to the acquired images.

Figure 7 shows the processed images of small portion of the images with the different threshold rages from 5 to 25 . Through these trials, threshold of 25 is chosen for influences reduction. Geometric correction is applied to the acquired camera images after extraction of intensive study areas. Figure 8 (a) and (b) show the resultant corrected images acquired on 18 and 22 August 2013, respectively.

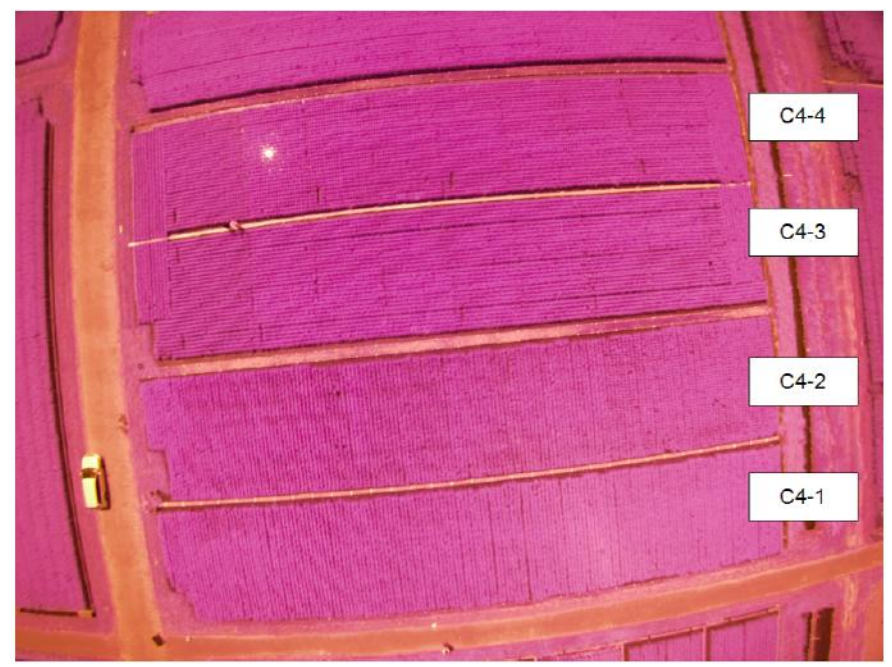

Fig. 5. Example of acquired camera image on 18 August 2013

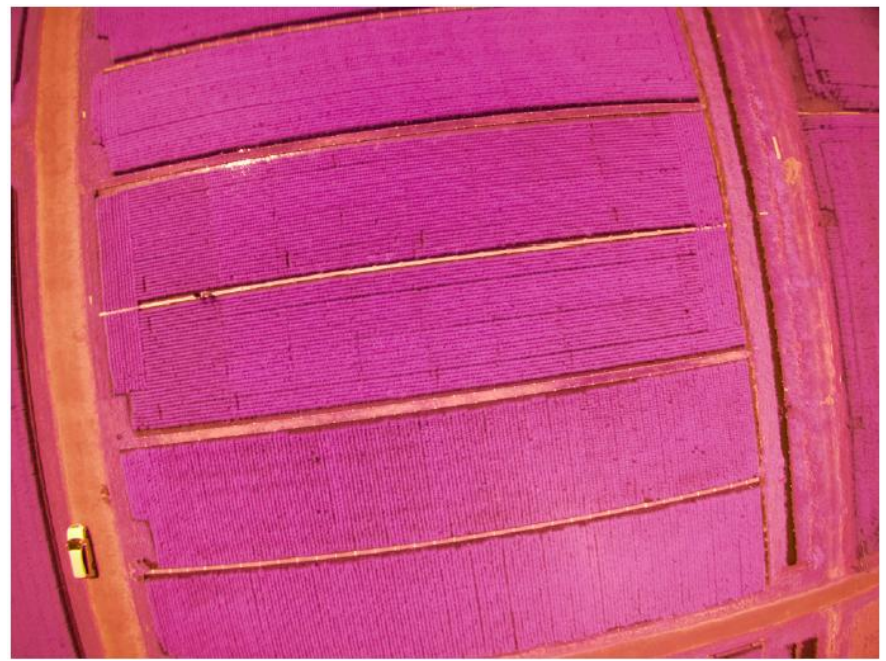

(a)August 18

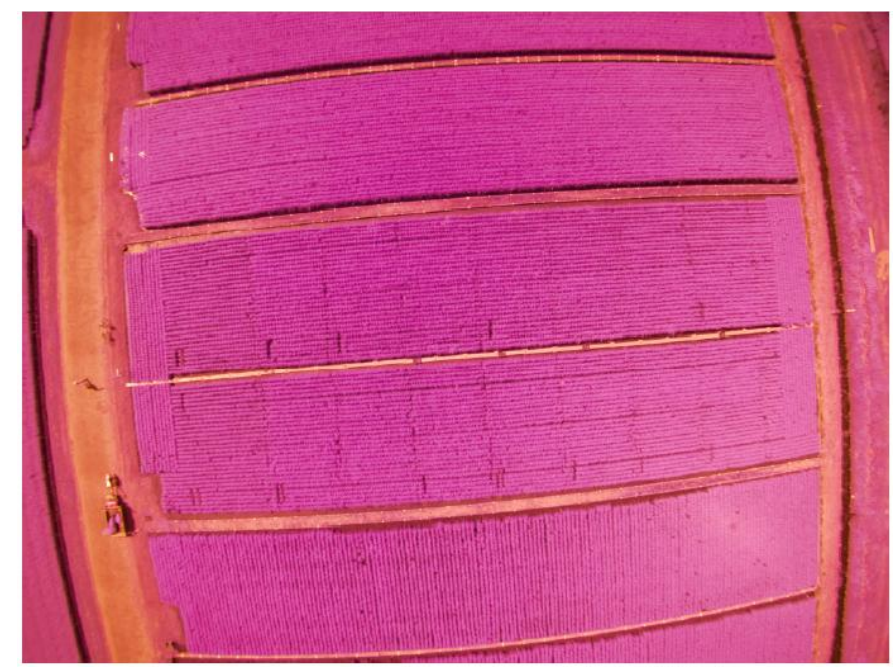

(b)August 22

Fig. 6. Camera images acquired on 18 and 22 August 2013
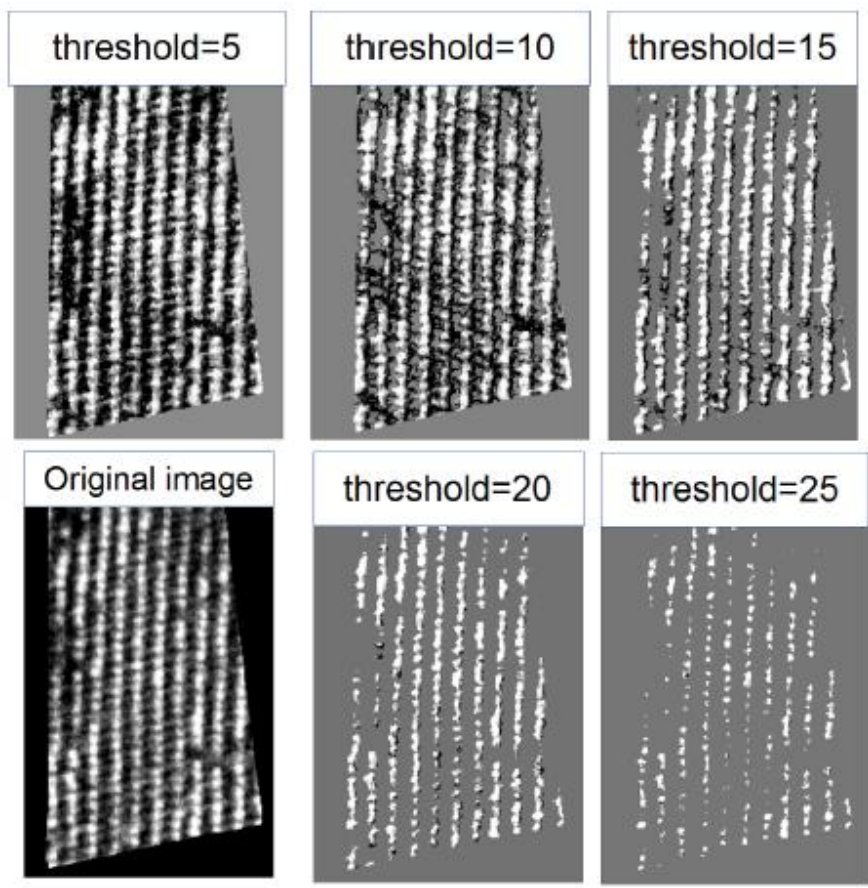

threshold $=25$

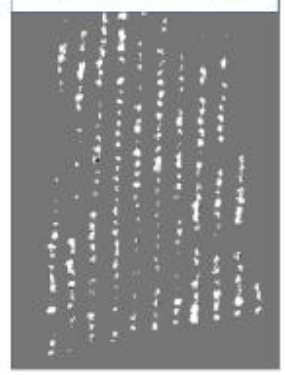

Fig. 7. Processed images of small portion of the images with the different threshold rages from 5 to 25 .

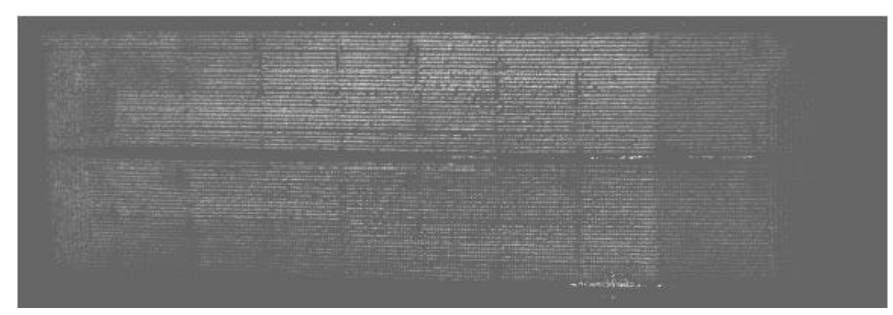

(a)August 18 


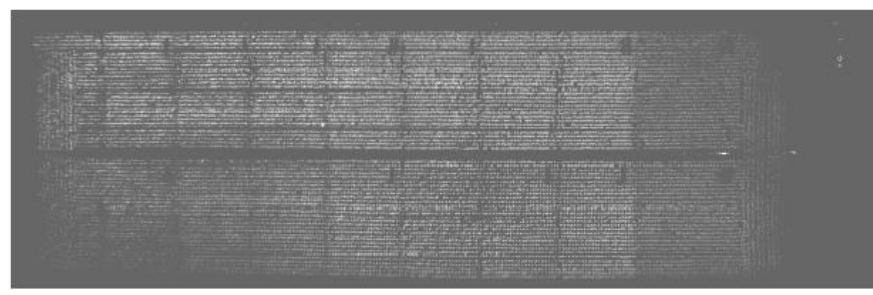

(b)August 22

Fig. 8. Resultant images of geometrically corrected which are acquired on 18 and 22 August 2013

On the other hand, measured nitrogen contents in rice leaves of rice paddy fields of partitioned $\mathrm{A} 1$ to $\mathrm{A} 8$ and $\mathrm{B} 1$ to B8 on 14 and 22 August 2013 are shown in Table 2 and 3, respectively. Nitrogen of chemical fertilizer, water management as well as plant density are different from each other partitioned rice paddy fields as aforementioned. Nitrogen content in the rice leaves seem to reflect the fact of chemical fertilizer of nitrogen, water supply management, and plantation density, obviously.

TABLE II. MEASURED Nitrogen CONTENT IN RicE LEAVES ON 14 AUGUST 2013

\begin{tabular}{|l|r|}
\hline Farm Area & Nitrogen (\%) \\
\hline A1 & 2.61 \\
\hline A3 & 2.85 \\
\hline A5 & 2.84 \\
\hline A8 & 2.77 \\
\hline B1 & 2.82 \\
\hline B3 & 2.74 \\
\hline B5 & 3.16 \\
\hline B8 & 2.78 \\
\hline
\end{tabular}

TABLE III. MEASURED NITROGEN CONTENT IN RICE LEAVES ON 22 AUGUST 2013

\begin{tabular}{|l|r|}
\hline Farm Area & Nitrogen (\%) \\
\hline A1 & 2.46 \\
\hline A2 & 2.88 \\
\hline A4 & 2.97 \\
\hline A5 & 2.89 \\
\hline A6 & 2.67 \\
\hline A8 & 3.22 \\
\hline B1 & 2.33 \\
\hline B2 & 2.79 \\
\hline B4 & 2.84 \\
\hline B5 & 2.85 \\
\hline B6 & 2.96 \\
\hline B8 & 3.14 \\
\hline
\end{tabular}

Relation between nitrogen as well as protein contents and NDVI for each paddy fields for August 18 and 222013 are shown in Figure 9 to 12.

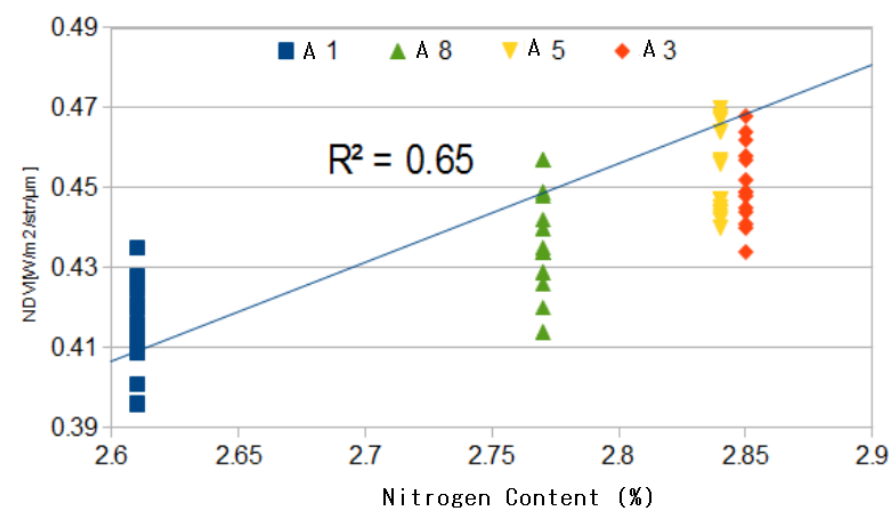

(a)A Site on August18 for all area

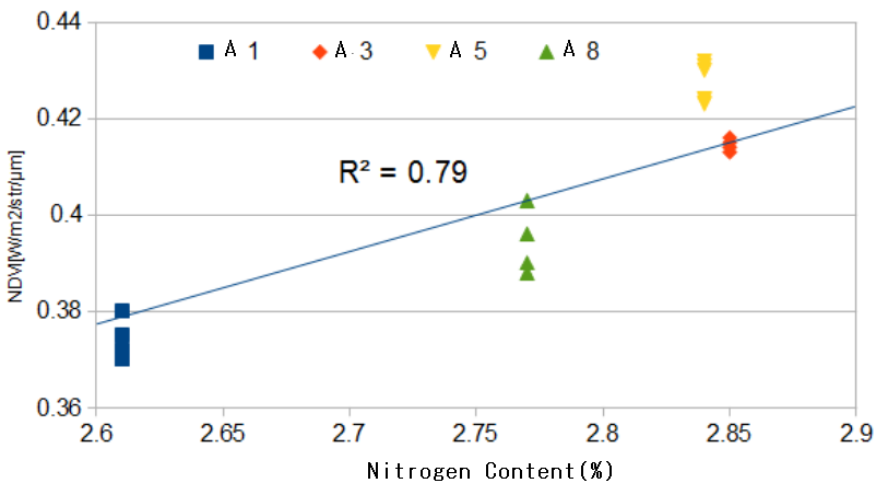

(b)A Site on August 18 for sampled areas

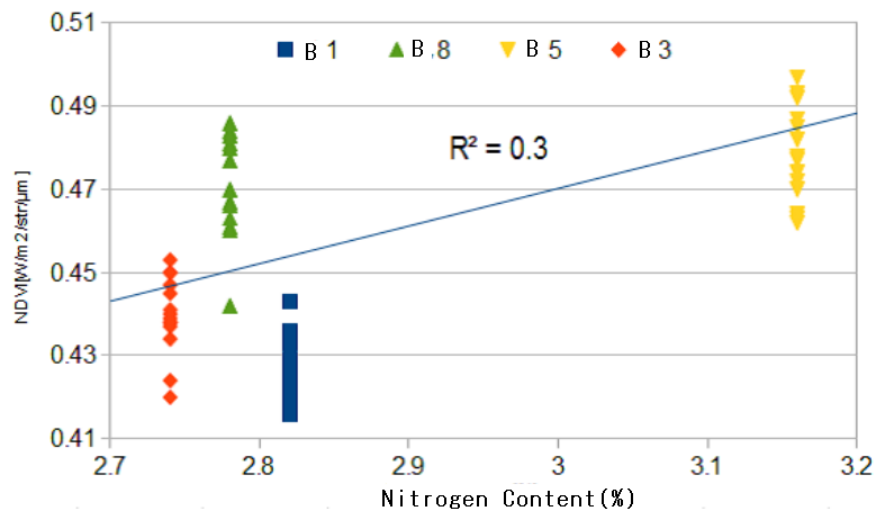

(c)B Site on August 18 for all area

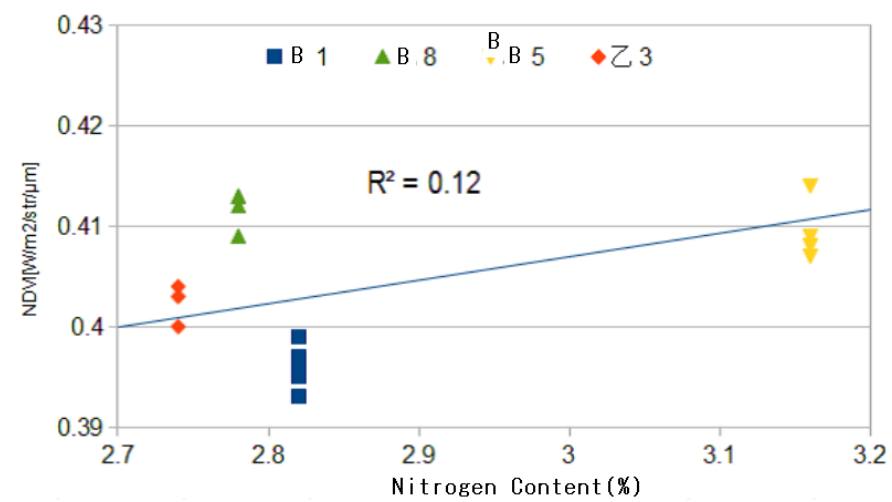

(d)B Site on August 18 for the sampled areas

Fig. 9. Relations between NDVI and the measured nitrogen content 


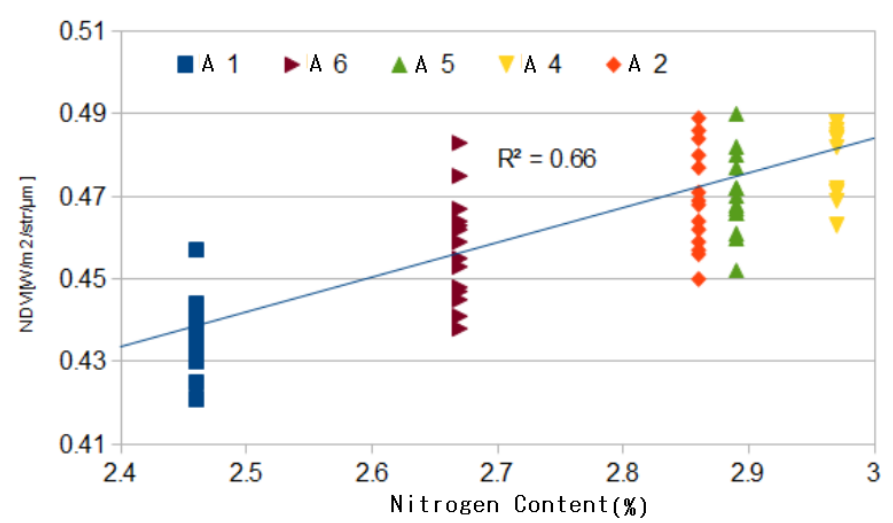

(a)A Site on August22 for all area

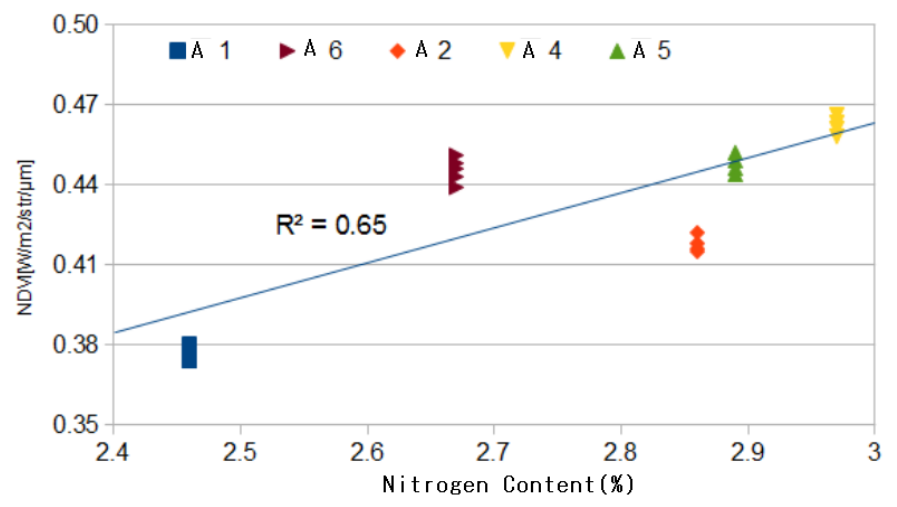

(b)A Site on August 22 for sampled areas

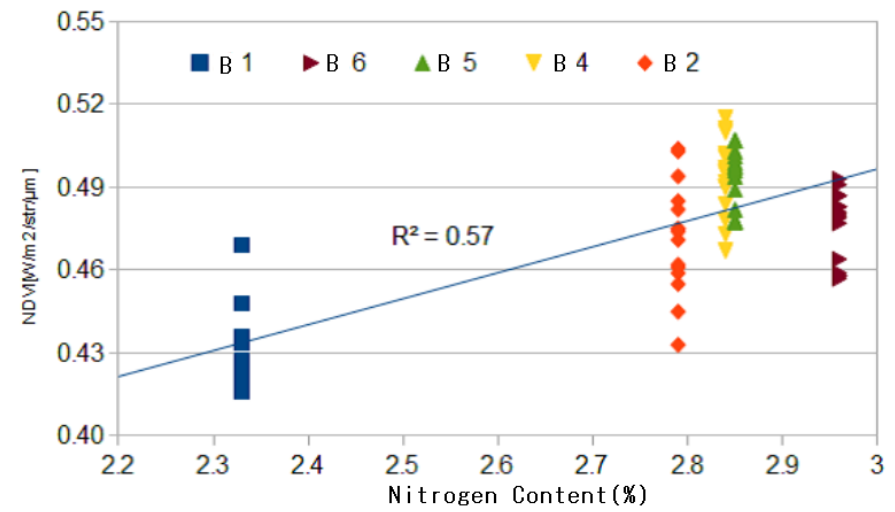

(c)B Site on August 22 for all area

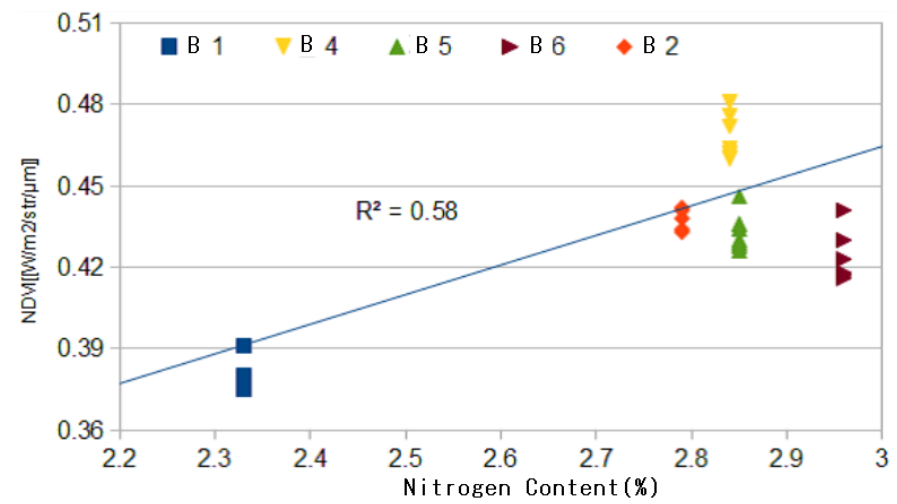

(d)B Site on August 22 for sampled areas

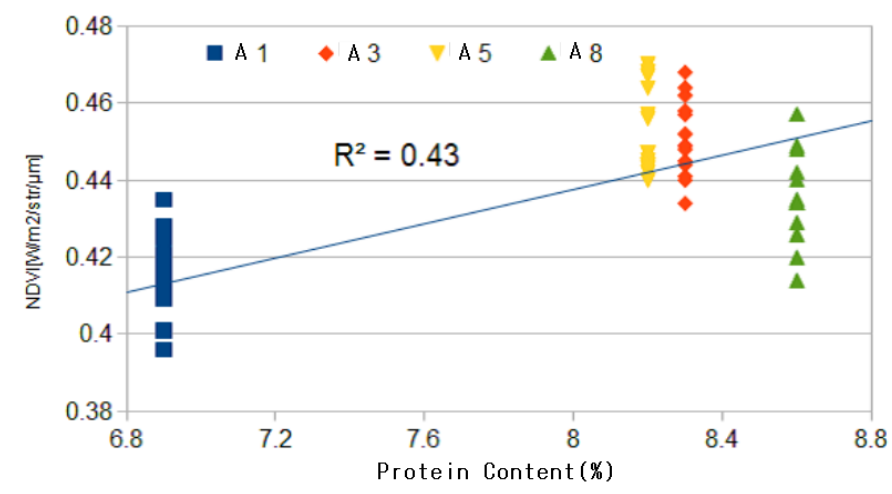

(a)A Site on August18 for all area

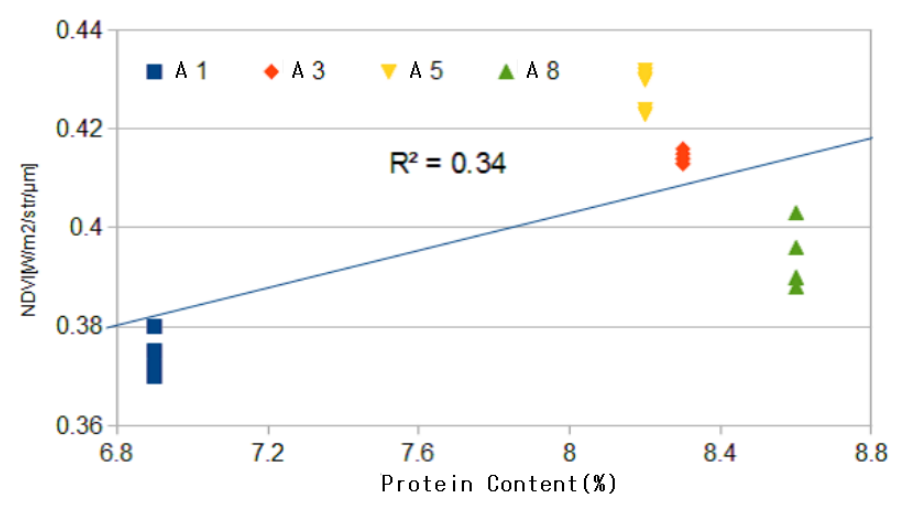

(b)A Site on August 18 for sampled areas

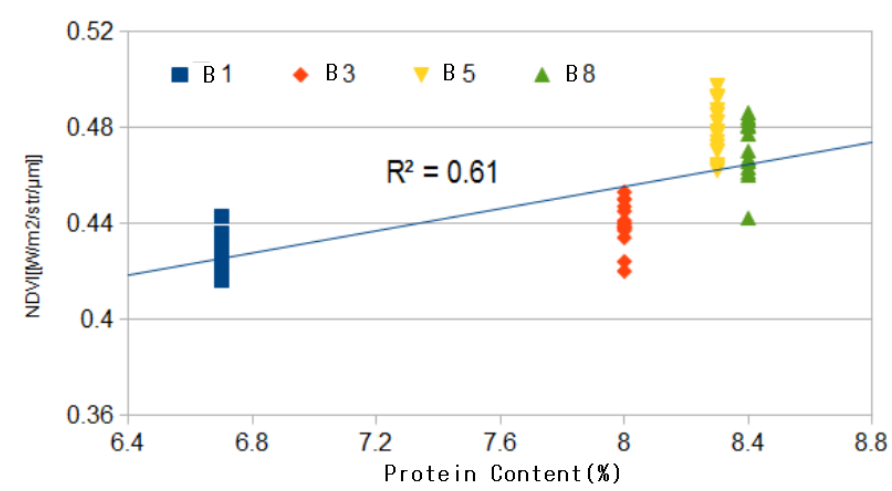

(c)B Site on August 18 for all area

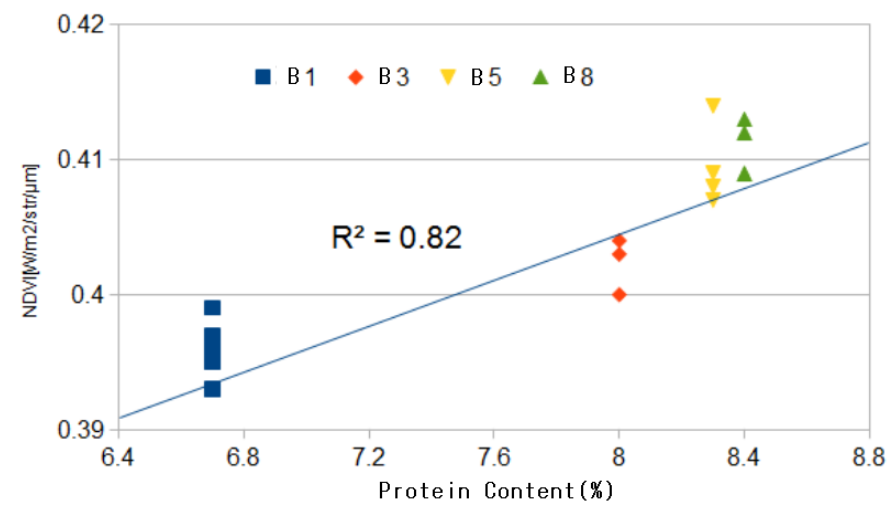

(d)B Site on August 18 for sampled areas

Fig. 11. Relations between NDVI and the measured Protein content

Fig. 10. Relations between NDVI and the measured nitrogen content 


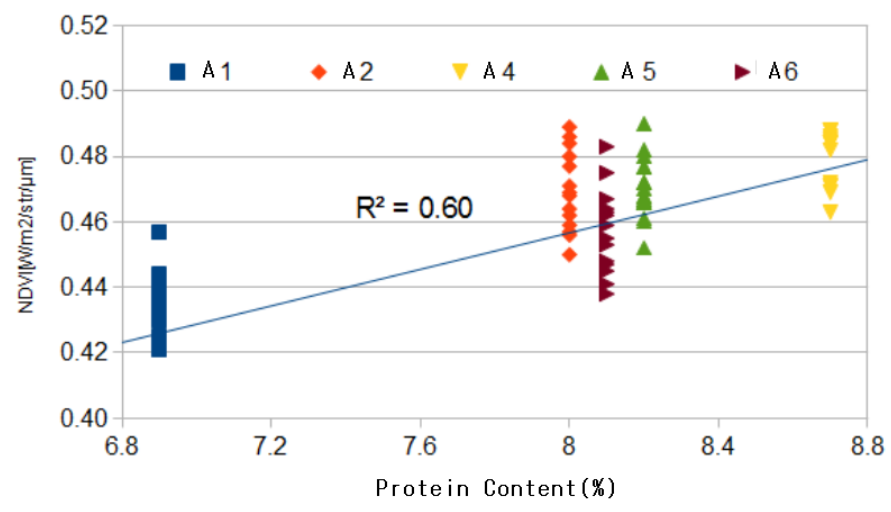

(a)A Site on August22 for all area

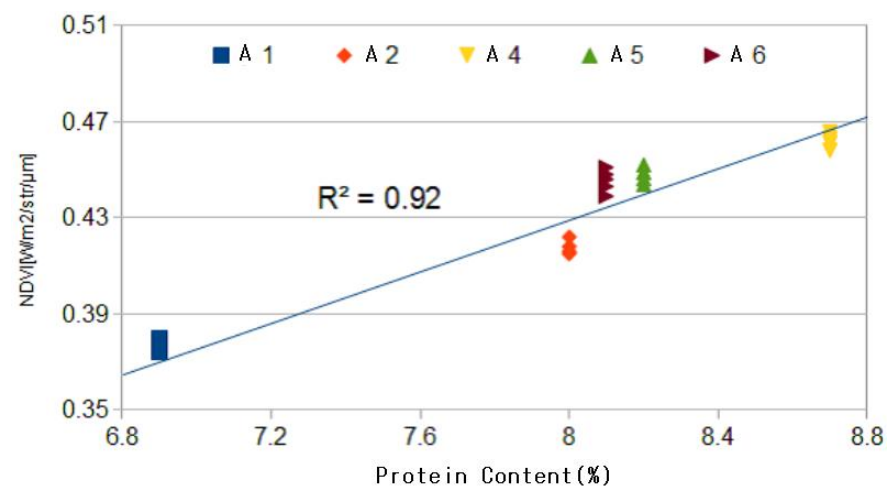

(b)A Site on August 22 for sampled areas

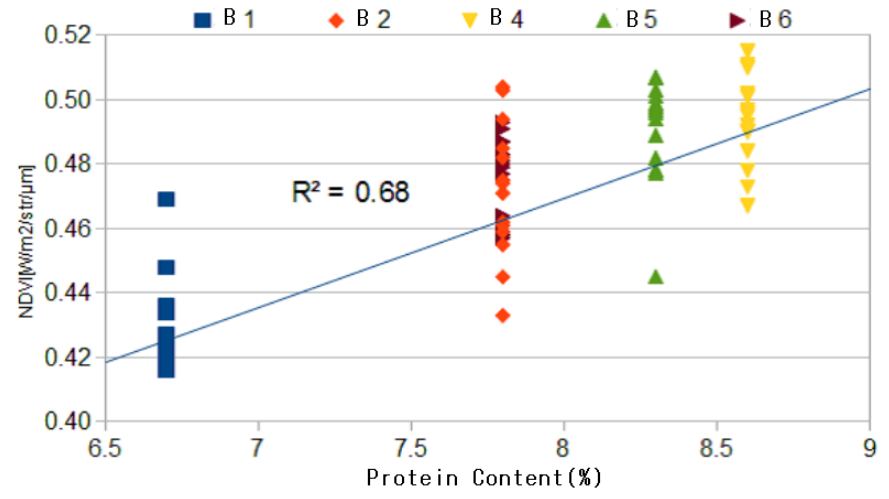

(c)B Site on August 22 for all area

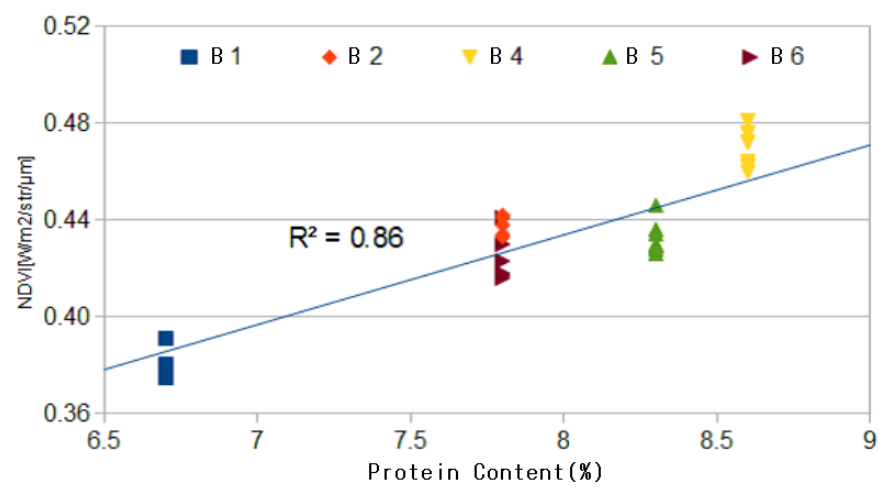

(d)B Site on August 22 for sampled areas

Fig. 12. Relations between NDVI and the measured protein content
The sampled areas imply that the locations of surrounding areas at which rice leaves are picked up for measurement of nitrogen content. Meanwhile, all area implies whole area of the strip of the rice paddy field. The correlation coefficients for the sampled areas are much greater than those of all area. Also variances for the sampled areas are much smaller than those for all area. More importantly, $\mathrm{R}$ square values of protein content are greater than those of nitrogen content. This implies that rice crop quality which represented by protein content is much reflected by the nitrogen of chemical fertilizer, water supply management, and rice leaves density rather than nitrogen content in rice leaves directly.

\section{CONCLUSION}

Estimation of protein content in rice crop and nitrogen content in rice leaves through regression analysis with Normalized Difference Vegetation Index: NDVI derived from camera mounted radio-control helicopter is proposed. Through experiments at rice paddy fields which is situated at Saga Prefectural Research Institute of Agriculture: SPRIA in Saga city, Japan, it is found that protein content in rice crops is highly correlated with NDVI which is acquired with visible and Near Infrared: NIR camera mounted on radio-control helicopter. It also is found that nitrogen content in rice leaves is correlated to NDVI as well. Protein content in rice crop is negatively proportional to rice taste. Therefore rice crop quality can be evaluated through NDVI observation of rice paddy field.

The correlation coefficients for the sampled areas are much greater than those of all area. Also variances for the sampled areas are much smaller than those for all area. More importantly, R square values of protein content are greater than those of nitrogen content. This implies that rice crop quality which represented by protein content is much reflected by the nitrogen of chemical fertilizer, water supply management, and rice leaves density rather than nitrogen content in rice leaves directly..

\section{ACKNOWLEDGMENT}

The author would like to thank Mr. Hideaki Munemoto of Saga University for his effort to conduct the experiments.

\section{REFRENCES}

[1] imating the growth and yield of rice, Journal of Crop Science, 58, 4, 673-683, 1989.

[2] Kohei Arai, Method for estimation of grow index of tealeaves based on Bi-Directional reflectance function:BRDF measurements with ground based netwrok cameras, International Journal of Applied Science, 2, 2, 52-62, 2011.

[3] Kohei Arai, Wireless sensor network for tea estate monitoring in complementally usage with Earth observation satellite imagery data based on Geographic Information System(GIS), International Journal of Ubiquitous Computing, 1, 2, 12-21, 2011.

[4] Kohei Arai, Method for estimation of total nitrogen and fiber contents in tealeaves with grond based network cameras, International Journal of Applied Science, 2, 2, 21-30, 2011.

[5] Kohei Arai, Method for estimation of damage grade and damaged paddy field areas sue to salt containing sea breeze with typhoon using remote sensing imagery data, International Journal of Applied Science,2,3,8492, 2011.

[6] Kohei Arai, Monte Carlo ray tracing simulation for bi-directional reflectance distribution function and grow index of tealeaves estimation, International Journal of Research and Reviews on Computer Science, 2, 6, 1313-1318, 2011. 
[7] K.Arai, Fractal model based tea tree and tealeaves model for estimation of well opened tealeaf ratio which is useful to determine tealeaf harvesting timing, International Journal of Research and Review on Computer Science, 3, 3, 1628-1632, 2012.

[8] K.Arai, H.Miyazaki, M.Akaishi, Determination of harvesting timing of tealeaves with visible and near infrared cameradata and its application to tea tree vitality assessment, Journal of Japanese Society of Photogrammetry and Remote Sensing, 51, 1, 38-45, 2012

[9] Kohei Arai, Osamu Shigetomi, Yuko Miura, Hideaki Munemoto, Rice crop field monitoring system with radio controlled helicopter based near infrared cameras through nitrogen content estimation and its distribution monitoring, International Journal of Advanced Research in Artificial Intelligence, 2, 3, 26-37, 201

\section{AUTHORS PROFILE}

Kohei Aarai He received BS, MS and PhD degrees in 1972, 1974 and 1982, respectively. He was with The Institute for Industrial Science and Technology of the University of Tokyo from April 1974 to December 1978 and also was with National Space Development Agency of Japan from January, 1979 to March, 1990. During from 1985 to 1987, he was with Canada Centre for Remote Sensing as a Post Doctoral Fellow of National Science and Engineering Research Council of Canada. He moved to Saga University as a Professor in Department of Information Science on April 1990. He was a councilor for the Aeronautics and Space related to the Technology Committee of the Ministry of Science and Technology during from 1998 to 2000 . He was a councilor of Saga University for 2002 and 2003. He also was an executive councilor for the Remote Sensing Society of Japan for 2003 to 2005. He is an Adjunct Professor of University of Arizona, USA since 1998. He also is Vice Chairman of the Commission-A of ICSU/COSPAR since 2008. He wrote 30 books and published 500 journal papers. 